\title{
Release of Somatostatin-like Immunoreactivity from Incubated Rat Hypothalamus and Cerebral Cortex
}

\author{
EFFECTS OF GLUCOSE AND GLUCOREGULATORY HORMONES
}

\author{
Michael Berelowitz, Daniel Dudlak, and lawrence A. Frohman, Division of \\ Endocrinology and Metabolism, Department of Medicine, Michael Reese \\ Hospital and Medical Center, University of Chicago, Illinois 60616
}

\begin{abstract}
A B S T R A C T Somatostatin (SRIF) is localized in the hypothalamus, extrahypothalamic brain, and throughout the gastrointestinal tract. Release of gastrointestinal SRIF-like immunoreactivity (SRIF-LI) is under nutrient regulation but the effect of nutrients on neural SRIF-LI is unknown. The present studies examined the effects of glucose uptake and metabolism and hormones influencing glucose disposition on SRIFLI release from medial basal hypothalamus (MBH) and cerebral cortex $(\mathrm{Cx})$ incubated in Krebs-Ringer bicarbonate containing bacitracin. After a preincubation to achieve stable secretion, tissues were incubated for 20 $\min$ in $14 \mathrm{mM}$ glucose (basal) and then, for $20 \mathrm{~min}$ in fresh medium with test materials. MBH SRIF-LI release was inversely related to medium glucose concentration with release in the absence of glucose $(235 \pm 42 \mathrm{pg} / \mathrm{MBH}$ per $20 \mathrm{~min})$ more than five times that in the presence of $25 \mathrm{mM}$ glucose $(46 \pm 4 \mathrm{pg} / 20$ min). In the presence of $14 \mathrm{mM}$ glucose MBH SRIFLI release was stimulated above basal by agents interfering with glucose uptake including 3-O-methylD-glucose $(42 \mathrm{mM} ; 70 \pm 5$ vs. $42 \pm 3 \mathrm{pg} / 20 \mathrm{~min}, P$ $<0.05$ ), phlorizin (50 mM; $351 \pm 63$ vs. $29 \pm 2 \mathrm{pg} / 20$ $\min , P<0.001)$ or cytochalasin B $(20 \mu \mathrm{M} ; 110 \pm 7$ vs. $22 \pm 2 \mathrm{pg} / 20 \mathrm{~min}, P<0.001)$. Inhibition of glucose metabolism by 2-deoxy-D-glucose resulted in dose-related stimulation of $\mathrm{MBH}$ SRIF-LI release (maximal at $28 \mathrm{mM} ; 201 \pm 28 \mathrm{pg} / 20 \mathrm{~min}$ vs. $32 \pm 4 \mathrm{pg} / 20 \mathrm{~min}$, $P<0.001$ ). Viability of MBH was unimpaired by incubation in the absence of glucose or following exposure to 2-deoxy-D-glucose as determined by reten-
\end{abstract}

\footnotetext{
Dr. Berelowitz and Dr. Frohman's current address is Division of Endocrinology and Metabolism, Department of Internal Medicine, University of Cincinnati College of Medicine, Cincinnati, $\mathrm{OH}$ 45267. Address reprint requests to $\mathrm{Dr}$. Berelowitz.

Received for publication 28 September 1981 and in revised form 18 December 1981.
}

tion of SRIF-LI responsiveness to stimulation by potassium $(60 \mathrm{mM})$ or neurotensin $(5 \mu \mathrm{M})$. In contrast, Cx SRIF-LI release was slightly inhibited by decreases in medium glucose and unaffected by inhibition of glucose uptake or metabolism. These results provide evidence for nutrient regulation of $\mathrm{MBH}$ but not $\mathrm{Cx}$ SRIF-LI release and may explain inhibition of growth hormone seen in the rat in response to hypoglycemia. Insulin (10 nM-1 $\mu \mathrm{M})$ stimulated $\mathrm{MBH}$ but not $\mathrm{Cx}$ SRIF-LI release while glucagon was without effect. Our previous demonstration that MBH SRIF-LI release was stimulated by somatomedin-C, but not insulin at physiologic concentrations, is consistent with an action of insulin through the somatomedin-C receptor at the doses studied. Our studies indicate a regional specificity for the control of SRIF secretion within the brain and suggests the possibility of a role for hypothalamic SRIF in metabolic regulation.

\section{INTRODUCTION}

Somatostatin (SRIF), ${ }^{1}$ the inhibitory hypothalamic regulator of pituitary growth hormone $(1,2)$ and thyrotropin $(3,4)$ release, is one of a group of peptides present in high concentration in the central nervous system (CNS), the pancreas, and gastrointestinal tract (5). Although the highest concentration of CNS SRIFlike immunoreactivity (SRIF-LI) is present in the median eminence (6), reflecting its hypophysiotropic role, the total content of SRIF-LI is considerably greater in the cerebral cortex (6). SRIF-LI is also present in D cells of the pancreatic islets (7) and throughout the gastrointestinal tract, with highest concentrations in the stomach $(5,6)$.

\footnotetext{
${ }^{1}$ Abbreviations used in this paper: CNS, central nervous system; SRIF, somatostatin; SRIF-LI, somatostatin-like immunoreactivity.
} 
Pancreatic and gastrointestinal SRIF exert an important role in nutrient homeostasis (8). Pancreatic SRIF inhibits the release of insulin (9) and glucagon (10), possibly through a local or paracrine effect, thereby influencing nutrient disposition. Gastric SRIF regulates acid secretion directly (11) and through local inhibition of antral gastrin release (12). In addition, gastrointestinal SRIF appears to have an inhibitory hormonal influence on nutrient, especially lipid, absorption (13). The demonstration that nutrients, in turn, stimulate the release of gastrointestinal SRIF-LI $(14,15)$ further supports a role for SRIF in nutrient regulation. Glucose stimulates pancreatic SRIF-LI (14) while lipids, especially free fatty acids, stimulate intestinal SRIF-LI release (15).

The role of CNS SRIF-LI in nutrient homeostasis is unknown. While hypothalamic SRIF-LI release has been demonstrated in response to a variety of stimuli including membrane depolarization $\left(60 \mathrm{mM} \mathrm{K}^{+}\right)(16$, 17), biogenic amines (dopamine) (17), peptides (neurotensin) (17), and hormones [growth hormone (18, $19)$, somatomedins $(20,21)$, triiodothyronine (22)], and cerebral cortical SRIF-LI release occurs in response to depolarizing stimuli (23), there is a paucity of information available concerning the response of hypothalamic or extrahypothalamic CNS SRIF-LI to nutrients.

The present studies were designed to investigate the effects of glucose uptake and metabolism and of the hormonal regulators of glucose utilization on SRIF-LI release in vitro from incubated rat hypothalamus and cerebral cortex.

\section{METHODS}

Experimental animals. Male Sprague-Dawley rats, weighing 150-200 g were housed under constant temperature $\left(24^{\circ} \mathrm{C}\right)$ and light $(14 \mathrm{~h})$-dark $(10 \mathrm{~h})$ cycles and were provided free access to laboratory rat chow and water. Animals from a single supplier (Locke Erikson, Melrose Park, IL) were used in all experiments.

Animals were decapitated with minimum handling and stress and the brain rapidly ( $<2 \mathrm{~min}$ ) removed to an ice-cold surface. The medial basal hypothalamus (defined by the lateral hypothalamic sulci, the mamillary bodies, and the optic chiasm; weight $22 \pm 3 \mathrm{mg} ; n=10$ ) was removed with curvedbladed scissors to a depth of $\sim 2 \mathrm{~mm}$ (level of the fornix). A cut made in the coronal plane at the level of the optic chiasm and a parallel cut $3 \mathrm{~mm}$ rostral to the first yielded a slice of brain from which a single strip of cerebral cortex could be defined (ventrally by the corpus callosum and its radiations and dorsally by the brain surface) and removed (weight; $124 \pm 4 \mathrm{mg} ; n=24$ ).

Hypothalamic and cerebral cortex incubation. Incubations were performed in $0.5 \mathrm{ml}$ Krebs-Ringer bicarbonate buffer containing bacitracin as previously reported $(19,21$, 22) with varying concentrations of glucose and other additions as described below. The sodium chloride concentration of the medium was varied as appropriate to provide a constant osmolality. After a preincubation to achieve stable secretion (60 min for hypothalamus, $80 \mathrm{~min}$ for cerebral cortex), tissues were incubated for $20 \mathrm{~min}$ (basal) in fresh medium containing $14 \mathrm{mM}$ glucose. At the end of the basal period medium was removed, fresh medium containing the stimulus under investigation was added and the tissue was incubated for an additional $20 \mathrm{~min}$. In some experiments one or two additional 20 -min incubations were performed in medium containing $14 \mathrm{mM}$ glucose with or without added stimuli. Media were removed after each incubation period, boiled for $5 \mathrm{~min}$, centrifuged and the supernatants stored at $-20^{\circ} \mathrm{C}$ until assayed.

Drugs. Stimuli used in the studies described included 60 $\mathrm{mM} \mathrm{KCl}$, neurotensin ( $5 \mu \mathrm{M}$, kindly provided by J. Rivier, Salk Institute), 3-O-methyl-D-glucose $(42 \mathrm{mM})$, phlorizin $(50$ $\mathrm{mM}$ ), and 2-deoxy-D-glucose (3-42 mM) (Sigma Chemical Co., St. Louis, MO), cytochalasin B $(20 \mu \mathrm{M}$, Aldrich Chemical Co., Inc., Milwaukee, WI), cytochalasin D $(20 \mu \mathrm{M}, \mathrm{Cal}-$ biochem-Behring Corp., American Hoechst Corp., San Diego, CA), crystalline porcine insulin and bovine-porcine glucagon (10 $\mathrm{nM}-1 \mu \mathrm{M}$, provided by Eli Lilly Research Laboratories, Indianapolis, IN).

Radioimmunoassay. SRIF radioimmunoassay was performed as previously described (22). The assay sensitivity was 1-2 pg SRIF/tube; $12-18 \mathrm{pg}$ SRIF produced $50 \%$ displacement from maximal binding. The interassay variation was $12 \%$ and the intraassay variation was $9 \%$.

Statistics. Comparisons between groups were performed using Student's nonpaired $t$ test and, where appropriate, an analysis of variance.

\section{RESULTS}

\section{Effect of medium glucose concentration on SRIF-LI release from hypothalamus and cerebral cortex}

Following a 20 -min basal incubation period in medium containing $14 \mathrm{mM}$ glucose, media were removed and replaced with fresh medium without glucose or with glucose concentrations ranging from 3 to $25 \mathrm{mM}$. Hypothalamic SRIF-LI release was inversely related to medium glucose concentration (Fig. 1A) with release in the absence of glucose $(235 \pm 42 \mathrm{pg} / \mathrm{hypo-}$ thalamus per $20 \mathrm{~min}$ ) more than five times that in the presence of $25 \mathrm{mM}$ glucose $(46 \pm 4 \mathrm{pg} / 20 \mathrm{~min})$. SRIFLI release from incubated cerebral cortex (Fig. 1B) exhibited a response opposite to that of the hypothalamus. Increasing glucose concentration resulted in a significant enhancement in SRIF-LI release that was maximal in the presence of $14 \mathrm{mM}$ glucose.

In two experiments hypothalamic and cerebral cortical SRIF-LI responses to potassium $(60 \mathrm{mM})$ or neurotensin $(5 \mu \mathrm{M})$ stimulation were compared during incubation in the absence or presence of $14 \mathrm{mM}$ glucose. Hypothalamic SRIF-LI release in the presence of 14 $\mathrm{mM}$ glucose was decreased compared with that in the absence of glucose without additional stimuli $(29 \pm 2$ vs. $149 \pm 20 \mathrm{pg} / 20 \mathrm{~min}, P<0.001)$ and in response to 

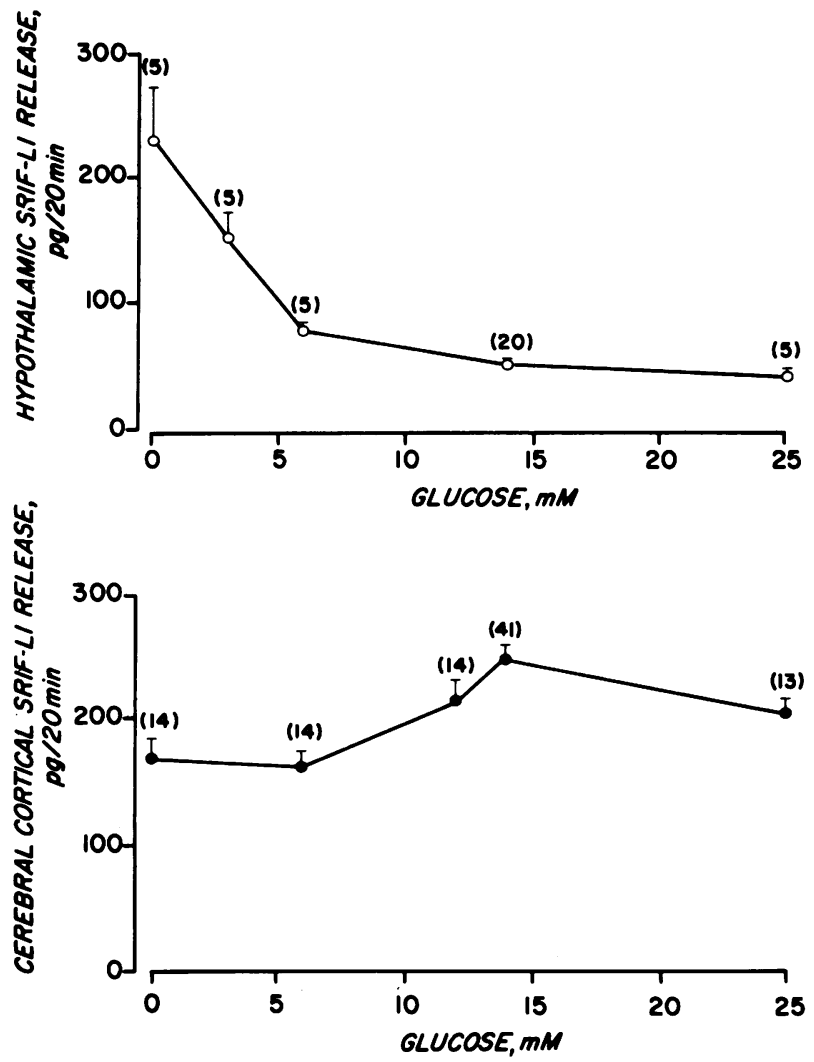

FIGURE 1 Effect of medium glucose concentration (0-25 $\mathrm{mM}$ ) on SRIF-LI release from incubated hypothalamus (upper panel) and cerebral cortex (lower panel). Release is shown as the mean $\pm \mathrm{SE}$. The number of incubations is in parentheses. potassium $(419 \pm 16$ vs. $576 \pm 37 \mathrm{pg} / 20 \mathrm{~min}, P<0.001)$ or neurotensin $(1,026 \pm 28$ vs. $1,170 \pm 24 \mathrm{pg} / 20 \mathrm{~min}, P$ $<0.001)$. However, the incremental rise of hypothalamic SRIF-LI release above basal was unaffected by either stimulus. Cerebral cortical SRIF-LI release in response to both stimuli were unaffected by medium glucose concentration (Fig. 2).

\section{Effects of agents influencing cellular glucose uptake or utilization on SRIF-LI release from hypothalamus and cerebral cortex}

In all experiments involving agents interfering with glucose metabolism hypothalamic and cerebral cortical incubations were performed in the presence of 14 $\mathrm{mM}$ glucose.

(a) 3-O-Methyl-D-glucose. Hypothalamic SRIF-LI release was stimulated by 3-O-methyl-D-glucose at a concentration of $42 \mathrm{mM}$ as compared with basal release (70 \pm 5 vs. $42 \pm 3 \mathrm{pg} / 20 \mathrm{~min}, P<0.05$ ) (Fig. 3).

(b) Phlorizin. Hypothalamic SRIF-LI release was markedly stimulated in the presence of $50 \mathrm{mM}$ phlorizin as compared with basal release ( $351 \pm 63$ vs. $29 \pm 2$ $\mathrm{pg} / 20 \mathrm{~min}, P<0.001$ ) (Fig. 3).

(c) Cytochalasin B and D. Hypothalamic SRIF-LI release was stimulated fivefold in the presence of 20 $\mu \mathrm{M}$ cytochalasin B $(110 \pm 7$ vs. $22 \pm 2 \mathrm{pg} / 20 \mathrm{~min}, P$ $<0.001$ ) while release from the cerebral cortex was unaffected ( $107 \pm 10$ vs. $152 \pm 28 \mathrm{pg} / 20 \mathrm{~min})$. Hypothalamic SRIF-LI release was unaltered by exposure to cytochalasin D, $20 \mu \mathrm{M}$ (Fig. 3).

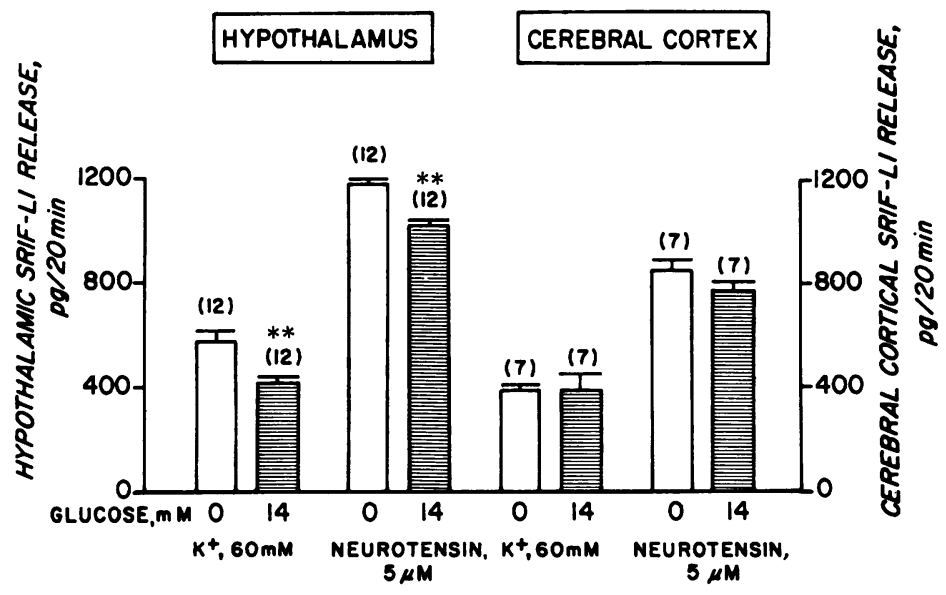

FIGURE 2 Effect of medium glucose concentration (0 or $14 \mathrm{mM})$ on SRIF-LI release from incubated hypothalamus and cerebral cortex. Release in response to stimulation by $60 \mathrm{mM} \mathrm{K}^{+}$ and neurotensin $(5 \mu \mathrm{M})$ is shown as the mean $\pm \mathrm{SE}^{\bullet}, P<0.001$. Basal hypothalamic SRIF-LI release: $0 \mathrm{mM} ; 149 \pm 20,14 \mathrm{mM} ; 29 \pm 2 \mathrm{pg} / 20 \mathrm{~min}$. Basal cerebral cortical SRIF-LI release: 0 $\mathrm{mM} ; 83 \pm 8,14 \mathrm{mM} ; 105 \pm 6 \mathrm{pg} / 20 \mathrm{~min}$. 


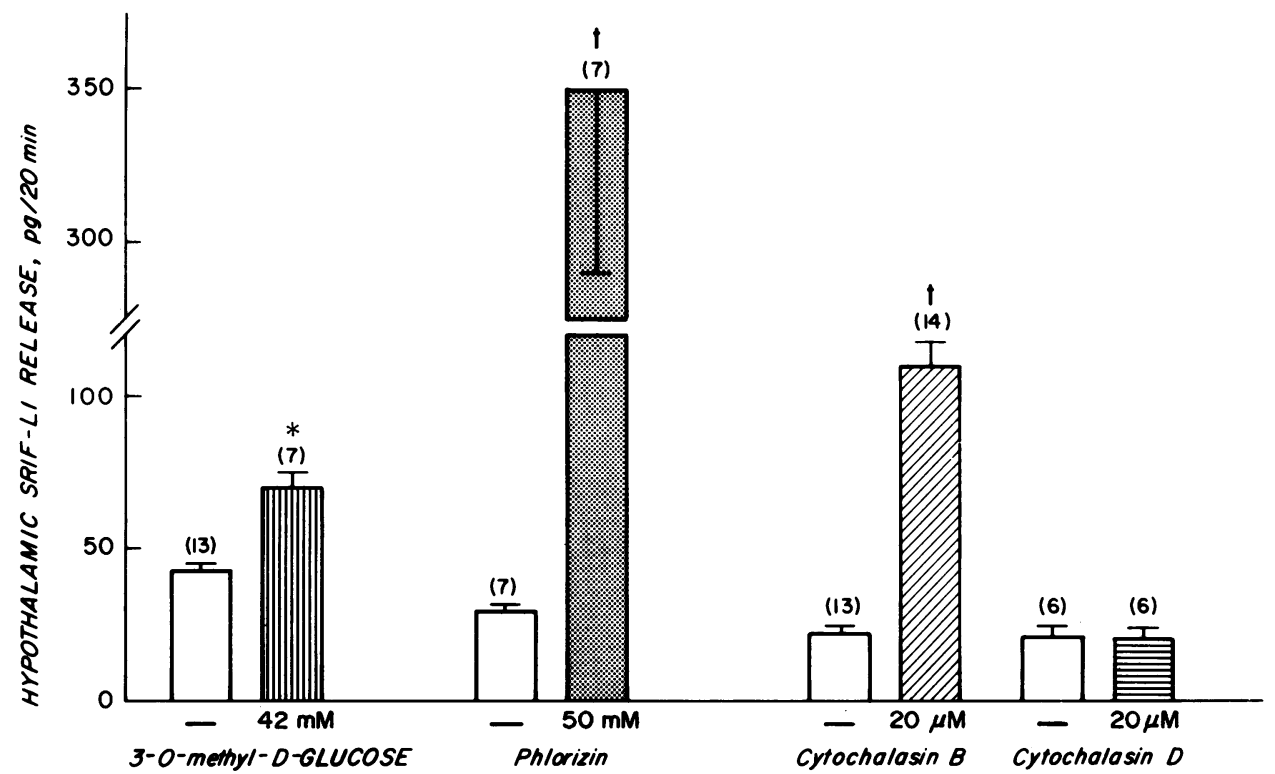

Figure 3 Effect of medium 3-O-methyl-D-glucose $(42 \mathrm{mM})$, phlorizin $(50 \mathrm{mM})$, cytochalasin B $(20 \mu \mathrm{M})$, and cytochalasin D $(20 \mu \mathrm{M})$ on SRIF-LI release from incubated hypothalamus ${ }^{\circ}$, $P<0.05 ;+, P<0.001$. See Fig. 1 for details.

(d) 2-Deoxy-D-glucose. Hypothalamic SRIF-LI release showed a dose-related stimulation in response to 2-deoxy-D-glucose that was maximal at $28 \mathrm{mM}(201 \pm 28$ $\mathrm{pg} / 20 \mathrm{~min})$ and represented a greater than sixfold increase over basal release $(32 \pm 4 \mathrm{pg} / 20 \mathrm{~min}) .2$-DeoxyD-glucose produced no significant effect on SRIF-LI release from the cerebral cortex in two experiments (Fig. 4).

To determine the effects of prior exposure to 2deoxy-D-glucose on hypothalamic and cerebral cortical SRIF-LI release, a further series of incubations were performed. Tissues were first incubated for 20 min in medium containing $14 \mathrm{mM}$ glucose alone or with 2-deoxy-D-glucose at concentrations ranging from 3 to $14 \mathrm{mM}$ (period 1). They were next incubated for $20 \mathrm{~min}$ in medium containing $14 \mathrm{mM}$ glucose (period 2). A dose-related stimulation of hypothalamic SRIFLI release occurred in the presence of 2-deoxy-D-glucose as in the previous experiment (period 1, data not shown). The stimulatory effect persisted following the removal of medium containing 2-deoxy-D-glucose (period 2, Fig. 5). Cerebral cortical SRIF-LI release was unaffected by exposure to 2-deoxy-D-glucose. Tissues were next incubated for $20 \mathrm{~min}$ in medium containing $14 \mathrm{mM}$ glucose together with $60 \mathrm{mM} \mathrm{K}^{+}$(period 3). Hypothalamic SRIF-LI release was stimulated in the presence of $60 \mathrm{mM} \mathrm{K}^{+}$during period 3 to a level that correlated with responses seen in presence of (period 1) and following (period 2) 2-deoxy-D-glucose.
Cerebral cortical SRIF-LI release in response to $60 \mathrm{mM}$ $\mathrm{K}^{+}$was unaffected by prior exposure to 2-deoxy-Dglucose up to $6 \mathrm{mM}$. SRIF-LI release from hypothalamus and cerebral cortex in response to $60 \mathrm{mM} \mathrm{K}^{+}$was diminished following prior exposure to $14 \mathrm{mM} \mathrm{2-}$ deoxy-D-glucose.

\section{Effect of hormones influencing glucose disposition on SRIF-LI release from hypothalamus and cerebral cortex}

Insulin stimulated hypothalamic SRIF-LI release in a dose-related manner. The lowest insulin concentration resulting in significant stimulation was $0.1 \mu \mathrm{M}$ $(49 \pm 4$ vs. $35 \pm 1 \mathrm{pg} / 20 \mathrm{~min}, P<0.05)$. Cerebral cortical SRIF-LI release was unaffected by insulin (Fig. 6; upper panel). Glucagon, in concentrations of $10 \mathrm{nM}$ to $1 \mu \mathrm{M}$ failed to influence SRIF-LI release from either hypothalamus or cerebral cortex (Fig. 6; lower panel).

\section{DISCUSSION}

The present study demonstrates that glucose is an important regulator of hypothalamic SRIF-LI release. Reductions in medium glucose concentration to levels below those normally present in rat plasma $(5-6 \mathrm{mM})$ resulted in increased hypothalamic SRIF-LI release, while increases in medium glucose concentration resulted in an inhibition of hypothalamic SRIF-LI re- 


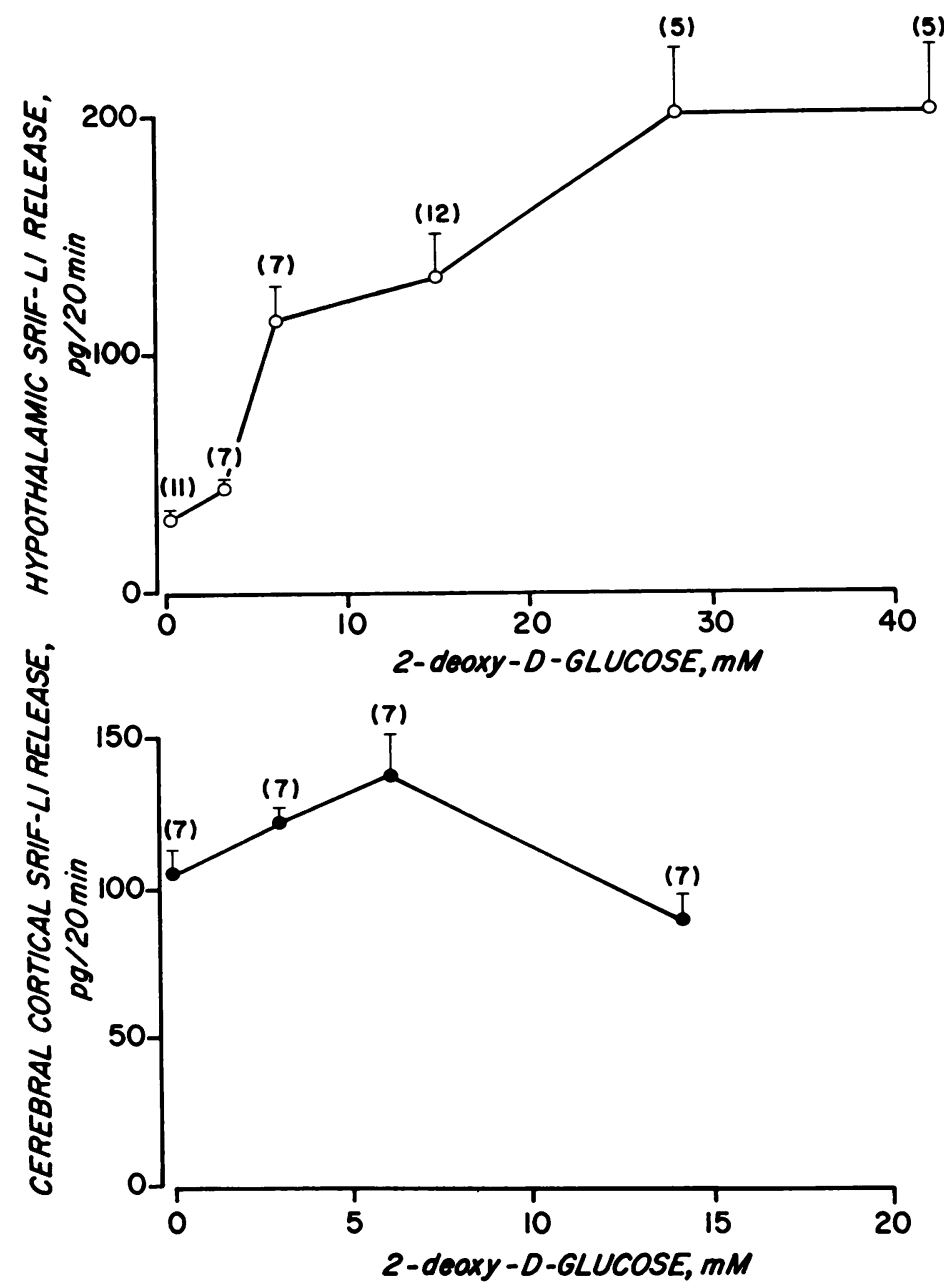

FIGURE 4 Effect of medium 2-deoxy-D-glucose (0-42 $\mathrm{mM})$ on SRIF-LI release from incubated hypothalamus (upper panel) and cerebral cortex (lower panel). See Fig. 1 for details.

lease. Incremental hypothalamic SRIF-LI responses to depolarizing stimulation and to neurotensin were unchanged in the absence of medium glucose suggesting that there was no loss of tissue viability during the short-term $(20 \mathrm{~min})$ incubation. To identify the mechanism of glucose-mediated inhibition of hypothalamic SRIF-LI release, the effect of various substances influencing cellular glucose uptake or metabolism was evaluated. Drugs that competed with (3-O-methyl-Dglucose) (24) or blocked (phlorizin) (25) glucose uptake stimulated hypothalamic SRIF-LI release, suggesting that glucose entry into cells is necessary for the inhibitory effect. Cytochalasin B, which inhibits glucose uptake as well as intracellular transport systems (26), stimulated hypothalamic SRIF-LI release. In contrast, cytochalasin $D$, which has similar effects on intracellular transport but is devoid of effects on glucose up- take (27), was without effect on SRIF-LI release supporting the hypothesis that glucose uptake into hypothalamic neurons is necessary to inhibit SRIF-LI release. The dose-related stimulatory effect of 2deoxy-D-glucose on hypothalamic SRIF-LI release indicates that glucose metabolism beyond the level of glucose-6-phosphorylation is required to inhibit SRIF release. Prior exposure to 2-deoxy-D-glucose had no effect on subsequent hypothalamic SRIF-LI responses to depolarizing stimulation though the influence of 2 deoxy-D-glucose persisted for at least $20 \mathrm{~min}$ after its removal from the medium as demonstrated by continued elevated basal hypothalamic SRIF-LI release.

The site of glucose action in the hypothalamus has not been defined in the present experiments. A direct suppressive effect on SRIF-containing neurons could result from glucose uptake and metabolism. Alter- 


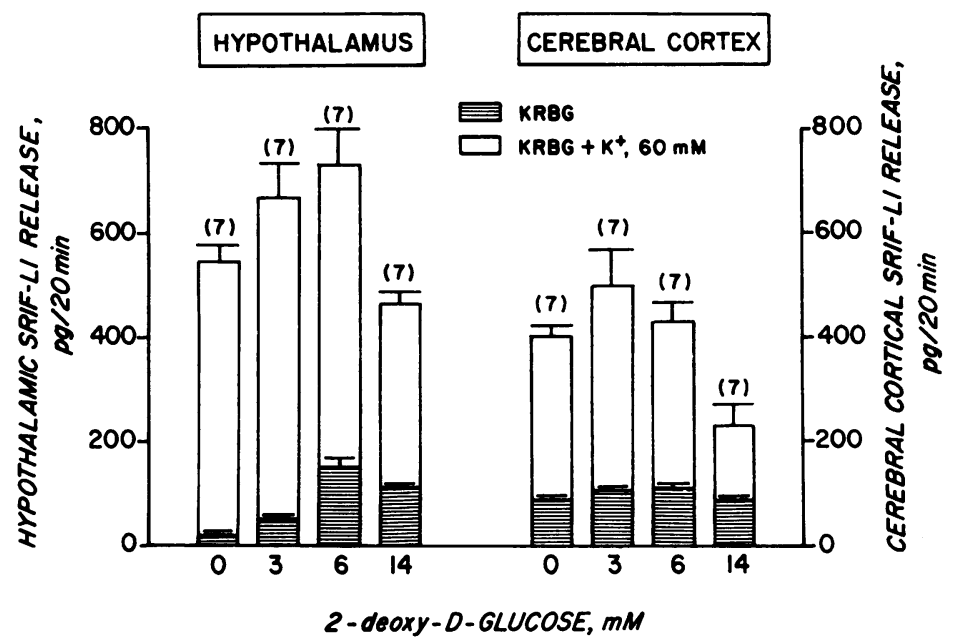

FIGURE 5 Effect of prior incubation in medium containing 2-deoxy-D-glucose (0-14 mM) on SRIF-LI release from incubated hypothalamus and cerebral cortex. Consecutive 20 -min incubations in medium alone (Krebs-Ringer bicarbonate buffer with glucose, hatched bars; period 2) then medium $+60 \mathrm{mM} \mathrm{K}{ }^{+}$(Krebs-Ringer bicarbonate buffer with glucose $+\mathrm{K}^{+}$, open bars; period 3) are shown as the mean $\pm \mathrm{SE}$. See Text for details.

nately, glucose activation of the hypothalamic glucoreceptor could stimulate SRIF-LI release directly, or through interneurons.

Our studies have demonstrated a marked CNS specificity of the effect of glucose on neural SRIF-LI; changes in the opposite direction in cerebral cortical and hypothalamic SRIF-LI release were produced by altering medium glucose concentration. Decreasing medium glucose concentration resulted in decreased cerebral cortical SRIF-LI release, a phenomenon that could represent a metabolic substrate energy-dependent process. A similar phenomenon may have occurred with hypothalamic SRIF-LI release that was masked by the area specific stimulatory effect of low medium glucose.

While the present studies provide the first evidence for nutrient regulation of hypothalamic SRIF-LI release, such regulation of gastrointestinal and pancreatic SRIF-LI has been well described. These observations raise the possibility of an integrated role for hypothalamic, gastrointestinal, and pancreatic SRIF in nutrient homeostasis. Evidence for such a role first appeared with the description of the inhibitory effects of exogenous SRIF on intestinal motility (28), gastric acid secretion (29), pancreatic exocrine secretion (30), and splanchnic blood flow (31). These effects result in delayed or decreased nutrient absorption (13) and complement the inhibitory action of SRIF on hormones important in nutrient absorption (cholecystokinin) (32) or disposition (insulin and glucagon) (33). In subsequent reports nutrients, most notably fatty acids (15), were shown to stimulate gastrointestinal and pancreatic SRIF-LI release, while glucose and amino acids stimulated predominantly pancreatic SRIF-LI release (14). Further support for a physiologic role of SRIF in fatty acid absorption was provided by experiments where passive immunization with anti-SRIF serum resulted in increased fatty acid absorption, suggesting that endogenous SRIF inhibits lipid absorption (34). Similar experiments have suggested that SRIF also acts physiologically to inhibit hormones important in nutrient homeostasis including gastrin (12), insulin (9), and glucagon (10).

While the present studies have documented an effect of ambient glucose concentration on hypothalamic SRIF-LI release, we have previously demonstrated that lesions of the ventromedial hypothalamus result in increased pancreatic SRIF-LI content and release indicating hypothalamic regulation of pancreatic SRIF (35). It thus appears that peripheral nutrient homeostasis can influence hypothalamic SRIF-LI whereas hypothalamic centers influence pancreatic hormone secretion and thus, in turn, nutrient disposition.

The effect of insulin and glucagon on CNS SRIF-LI release was determined to assess the effect of hormones influencing glucose disposition. Insulin resulted in a dose-related stimulation of hypothalamic SRIF-LI release that was apparent only at concentrations of 0.1 $\mu \mathrm{M}$ and greater. We have previously reported that insulin at physiologic concentrations $(4 \mathrm{nM})$ has no effect on hypothalamic SRIF-LI release (21). The high levels of insulin required to achieve stimulation of SRIF-LI 

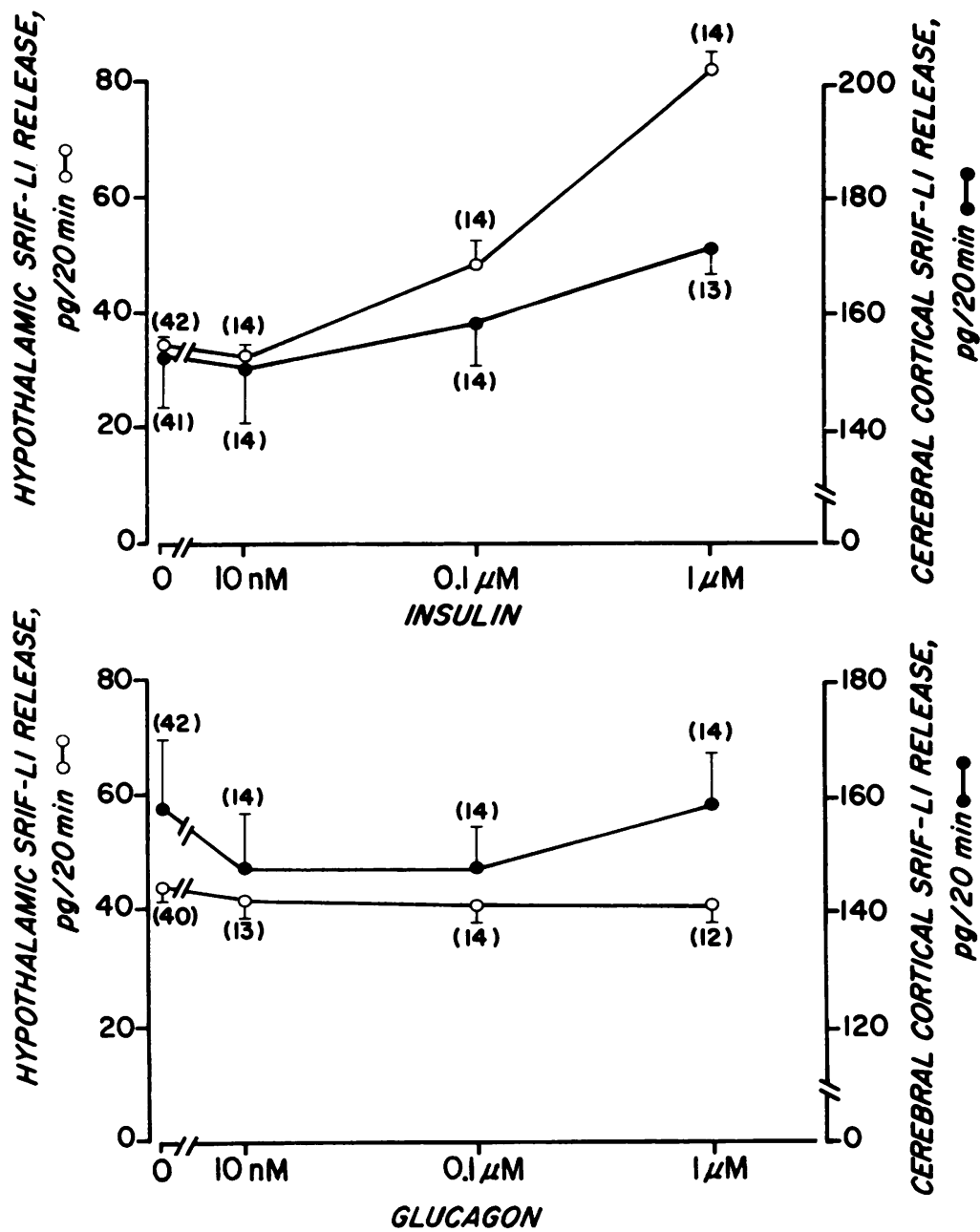

Figure 6 Effect of medium insulin (10 nM-1 $\mu \mathrm{M}$; upper panel) and glucagon (10 $\mathrm{nM}-1 \mu \mathrm{M}$; lower panel) on SRIF-LI release from incubated hypothalamus (open circles) and cerebral cortex (filled circles). See Fig. 1 for details.

release could possibly be explained by binding of insulin to a somatomedin-C receptor, an effect previously described in other tissues (36). We have previously demonstrated that somatomedin-C stimulates SRIF-LI release at physiologic concentrations $(5-50$ $\mathrm{ng} / \mathrm{ml}$ ) (21). The lack of stimulation of cerebral cortical SRIF-LI release by the same insulin concentrations provides further documentation of area specificity of the response.

In summary we have documented an inverse doserelated effect of glucose on hypothalamic but not cerebral cortical SRIF-LI release. The effect required the entry of glucose into cells and its subsequent metabolism. Insulin had no effect on hypothalamic SRIFLI release at physiologic concentrations but exhibited a stimulatory effect at high concentrations. This effect is not mediated by glucose entry into cells (which decreases SRIF-LI release) but may result from binding of insulin to a hypothalamic somatomedin-C receptor. These data provide an explanation for the observation of a decrease in serum growth hormone levels in rats during insulin-induced hypoglycemia (37). In man, however, the same stimulus results in growth hormone stimulation suggesting either that SRIF has a more prominent role in growth hormone regulation in the rat or that regulation of hypothalamic SRIF release differs in the two species.

Note added in proof. We have recently determined that synthetic neurotensin prepared by Peninsula Laboratories Inc., San Carlos, CA and by Bachem Laboratories, Inc., Torrance, CA fails to stimulate CNS SRIF-LI release. The ac- 
tivity responsible for the elevation of neural SRIF-LI seen in response to synthetic neurotensin provided by $\mathrm{Dr}$. Jean Rivier, Salk Institute, has been found to reside in a contaminant of the material and thus data obtained with this preparation should be disregarded.

\section{ACKNOWLEDGMENT}

This work was supported in part by U.S. Public Health Service grants AM 26312 and AM 18722.

\section{REFERENCES}

1. Ferland, L., F. Labrie, A. Arimura, and A. V. Schally. 1977. Stimulated release of hypothalamic growth hormone-releasing activity by morphine and pentobarbital. Mol. Cell. Endocr. 6: 247-252.

2. Tannenbaum, G. S., J. Epelbaum, E. Colle, P. Brazeau, and J. B. Martin. 1978. Antiserum to somatostatin reverses starvation-induced inhibition of growth hormone but not insulin secretion. Endocrinology. 102: 19091914.

3. Ferland, L., F. Labrie, M. Jobin, A. Arimura, and A. V. Schally. 1976. Physiological role of somatostatin in the control of growth hormone and thyrotropin secretion. Biochem. Biophys. Res. Commun. 68: 149-156.

4. Arimura, A., and A. V. Schally. 1976. Increase in basal and thyrotropin-releasing hormone-stimulated secretion of thyrotropin by passive immunization with antiserum to somatostatin in rats. Endocrinology. 98: 1069-1072.

5. Kronheim, S., M. Berelowitz, and B. L. Pimstone. 1976. A radioimmunoassay for growth hormone release-inhibiting hormone: method and quantitative tissue distribution. Clin. Endocrinol. 5: 619-630.

6. Patel, Y. C., and S. Reichlin. 1978. Somatostatin in hypothalamus, extrahypothalamic brain, and peripheral tissues of the rat. Endocrinology. 102: 523-530.

7. Dubois, M. P. 1975. Immunoreactive somatostatin is present in discrete cells of the endocrine pancreas. Proc. Natl. Acad. Sci. U.S.A. 72: 1340-1343.

8. Schusdziarra, V. 1980. Somatostatin-a regulatory modulator connecting nutrient entry and metabolism. Horm. Metab. Res. 12: 563-577.

9. Taniguchi, H., M. Utsumi, M. Hasegawa, T. Kobayashi, Y. Watanabe, K. Murakami, M. Seki, A. Tsutou, H. Makimura, M. Sakoda, and S. Baba. 1977. Physiologic role of somatostatin. Insulin release from rat islets treated by somatostatin antiserum. Diabetes. 26: 700-702.

10. Barden, N., M. Lavoie, A. Dupont, J. Cote, and J-P Cote. 1977. Stimulation of glucagon release by addition of anti-somatostatin serum to islets of Langerhans in vitro. Endocrinology. 101: 635-638.

11. Alumets, J., M. Ekelund, H. A. El Munshid, R. Hakanson, I. Loren, and F. Sundler. 1979. Topography of somatostatin cells in the stomach of the rat: possible functional significance. Cell Tissue Res. 202: 177-188.

12. Larsson, L-I., N. Goltermann, L. DeMagistris, J. F. Rehfeld, and T. W. Schwartz. 1979. Somatostatin cell processes as pathways for paracrine secretion. Science (Wash., D.C.). 205: 1393-1395.

13. Schusdziarra, V., V. Harris, A. Arimura, and R. H. Unger. 1979. Evidence for a role of splanchnic somatostatin in the homeostasis of ingested nutrients. Endocrinology. 104: 1705-1708.

14. Schusdziarra, V., D. Rouiller, A. Pietri, V. Harris, E.
Zyznar, J. M. Conlon, and R. H. Unger. 1979. Pancreatic and gastric release of somatostatin-like immunoreactivity during the intestinal phase of a meal. Am. J. Physiol. 237: 555-560.

15. Wasada, T., B. Howard, R. E. Dobbs, and R. H. Unger. 1980. Evidence for a role of free fatty acids in the regulation of somatostatin secretion in normal and alloxan diabetic dogs. J. Clin. Invest. 66: 511-516.

16. Berelowitz, M., S. Kronheim, and B. Pimstone. 1978. Potassium stimulated calcium-dependent release of immunoreactive somatostatin from incubated rat hypothalamus. J. Neurochem. 31: 1537-1539.

17. Maeda, K., and L. A. Frohman. 1980. Release of somatostatin and thyrotropin-releasing hormone from rat hypothalamic fragments in vitro. Endocrinology. 106: 1837-1842.

18. Sheppard, M. C., S. Kronheim, and B. L. Pimstone, 1978. Stimulation by growth hormone of somatostatin release from the rat hypothalamus in vitro. Clin. Endocrinol. 9: $583-586$.

19. Berelowitz, M., S. L. Firestone, and L. A. Frohman. 1981. Effects of growth hormone excess and deficiency on hypothalamic somatostatin content and release and on tissue somatostatin distribution. Endocrinology. 109: 714-719.

20. Sheppard, M. C., B. L. Pimstone, S. Hendricks, S. Kronheim, B. Shapiro, and L. Fryklund. 1979. SomatomedinA effect on somatostatin release from rat hypothalamus and growth hormone release from perfused pituitary. In Molecular Endocrinology. J. MacIntyre and M. Szelke, editors. Elsevier North-Holland Inc., New York. 141144.

21. Berelowitz, M., M. Szabo, L. A. Frohman, S. Firestone, L. Chu, and R. L. Hintz, 1981. Somatomedin-C mediates growth hormone negative feedback by effects on both the hypothalamus and the pituitary. Science (Wash., D.C.). 212: 1279-1281.

22. Berelowitz, M., K. Maeda, S. Harris, and L. A. Frohman. 1980. The effects of alterations in the pituitary-thyroid axis on hypothalamic content and in vitro release of somatostatin-like immunoreactivity. Endocrinology. 107: 24-29.

23. Lee, S. L., V. Havlicek, A. E. Panerai, and H. G. Friesen. 1979. High $\mathrm{K}^{+}$-induced release of somatostatin from the cortical preparation of rat brain. Experientia (Basel). 35: 351-352.

24. Morgan, H. E., D. M. Regen, and C. R. Park. 1964. Identification of a mobile carrier-mediated sugar transport system in muscle. J. Biol. Chem. 293: 369-374.

25. Battaglia, F. C., and P. J. Randle. 1960. Regulation of glucose uptake by muscle. Biochem. J. 75: 408-416.

26. Drewes, L. R., R. W. Horton, A. L. Betz, and D. D. Gilboe. 1977. Cytochalasin B inhibition of brain glucose transport and the influence of blood components on inhibitor concentration. Biochim. Biophys. Acta. 471: 447486.

27. McDaniel, M., C. Roth, J. Fink, G. Fyfe, and P. Lacy. 1975. Effects of cytochalasins $B$ and $D$ on alloxan inhibition of insulin release. Biochem. Biophys. Res. Commun. 66: 1089-1096.

28. Efendic, S., and O. Mattsson. 1978. Effect of somatostatin on intestinal motility. Acta Radiol. Diagn. 19: 348352.

29. Gomez-Pan, A., J. D. Reed, M. Albinus, B. Shaw, R. Hall, G. M. Besser, D. H. Coy, A. J. Kastin, and A. V. Schally. 1975. Direct inhibition of gastric acid and pepsin secre- 
tion by growth hormone release-inhibiting hormone in cats. Lancet. I: 888-890.

30. Dollinger, H. C., S. Raptis, and E. F. Pfeiffer. 1976. Effects of somatostatin on exocrine and endocrine pancreatic function stimulated by intestinal hormones in man. Horm. Metab. Res. 8: 74-78.

31. Jaspan, J., K. Polonsky, M. Lewis, and A. R. Moossa. 1979. Reduction in portal vein blood flow by somatostatin. Diabetes. 28: 888-892.

32. Schlegel, W., S. Raptis, R. F. Harvey, J. M. Oliver, and E. F. Pfeiffer. 1977. Inhibition of cholecystokinin-pancreozymin release by somatostatin. Lancet II: 166-167.

33. Koerker, D. J., W. Ruch, E. Chideckel, J. Palmer, C. J. Goodner, J. Ensinck, and C. C. Gale. 1974. Somatostatin: hypothalamic inhibitor of the endocrine pancreas. Science (Wash., D.C.). 184: 482-484.

34. Schusdziarra, V., E. Zyznar, D. Rouiller, G. Boden,
J. C. Brown, A. Arimura, and R. H. Unger. 1980 Splanchnic somatostatin: a hormonal regulator of nutrient homeostasis. Science (Wash., D.C.). 207: 530-532.

35. Goto, Y., R. G. Carpenter, M. Berelowitz, and L. A. Frohman. 1980. Effect of ventromedial hypothalamic lesions on the secretion of somatostatin, insulin, and glucagon by the perfused rat pancreas. Metab. Clin. Exp. 29: 986-990.

36. Phillips, L. S., and R. Vassilopoulou-Sellin. 1980. Somatomedins. N. Engl. J. Med. 302: 371-380 and 438446.

37. Schalch, D. S., and S. Reichlin. 1968. Stress and growth hormone release. In Growth Hormone. Proceedings of the First International Symposium, Milan, Italy, 1967. A. Pecile and E. E. Muller, editors. Excerpta Medica Foundation, New York. 211-225. 